\title{
Effect of vfr mutation on global gene expression and catabolite repression control of Pseudomonas aeruginosa
}

\author{
Sang-Jin Suh, ${ }^{1} \dagger$ Laura J. Runyen-Janecky, ${ }^{1} \neq$ Tricia C. Maleniak, ${ }^{1}$ \\ Paul Hager, ${ }^{2}$ Carolyn H. MacGregor, ${ }^{2}$ Nicolette A. Zielinski-Mozny, ${ }^{1} \mathbb{S}$ \\ Paul V. Phibbs, Jr' ${ }^{2}$ and Susan E. H. West ${ }^{1}$
}

1 Department of Pathobiological Sciences, School of Veterinary Medicine, University of Wisconsin-Madison, Madison, WI 53706, USA

2 Department of Microbiology and Immunology, East Carolina University School of Medicine, Greenville, NC 27858, USA
Author for correspondence: Susan E. H. West. Tel: +1 608263 7884. Fax: +1 6082637884. e-mail:wests@svm.vetmed.wisc.edu

Vfr of Pseudomonas aeruginosa is $91 \%$ similar to the CAMP receptor protein (CRP) of Escherichia coli. Based on the high degree of sequence homology between the two proteins, the question arose whether Vfr had a global regulatory effect on gene expression for $P$. aeruginosa as CRP did for $E$. coli. This report provides two-dimensional polyacrylamide gel electrophoretic evidence that $\mathrm{Vfr}$ is a global regulator of gene expression in $P$. aeruginosa. In a vfr101: aacC1 null mutant, at least 43 protein spots were absent or decreased when compared to the proteome pattern of the parent strain. In contrast, 17 protein spots were absent or decreased in the parent strain when compared to the vfr101:: aacC1 mutant. Thus, a mutation in vfr affected production of at least 60 proteins in $P$. aeruginosa. In addition, the question whether $V f r$ and CRP shared similar mechanistic characteristics was addressed. To ascertain whether Vfr, like CRP, can bind CAMP, Vfr and CRP were purified to homogeneity and their apparent dissociation constants $\left(K_{\mathrm{d}}\right)$ for binding to CAMP were determined. The $K_{\mathrm{d}}$ values were $1.6 \mu \mathrm{M}$ for Vfr and $0.4 \mu \mathrm{M}$ for CRP, suggesting that these proteins have a similar affinity for CAMP. Previously the authors had demonstrated that Vfr could complement a crp mutation and modulate catabolite repression in $E$. coli. This study presents evidence that $\mathbf{V f r}$ binds to the $E$. coli lac promoter and that this binding requires the presence of CAMP. Finally, the possible involvement of $\mathrm{Vfr}$ in catabolite repression control in $P$. aeruginosa was investigated. It was found that succinate repressed production of mannitol dehydrogenase, glucose-6-phosphate dehydrogenase, amidase and urocanase both in the parent and in two vfr null mutants. This implied that catabolite repression control was not affected by the vfr null mutation. In support of this, the cloned vfr gene failed to complement a mutation in the $P$. aeruginosa crc gene. Thus, although $\mathbf{V f r}$ is structurally similar to CRP, and is a global regulator of gene expression in $P$. aeruginosa, Vfr is not required for catabolite repression control in this bacterium.

Keywords: Vfr, catabolite repression control, global regulator, cAMP binding, cAMP receptor protein

\section{INTRODUCTION}

Pseudomonas aeruginosa is a Gram-negative opportunistic bacterial pathogen that primarily affects cystic fibrosis patients and immunocompromised patients. $P$. aeruginosa is found ubiquitously in nature and the recently completed genome sequencing demonstrated that it has the largest bacterial genome among the

† Present address: Department of Microbiology and Immunology, Medical College of Virginia campus of Virginia Commonwealth University, Richmond, VA 23298-0678, USA.

$\ddagger$ Present address: Department of Cellular and Molecular Toxicology, Abbott Laboratories, Abbott Park, IL 60064-6104, USA.

Abbreviation: CRP, CAMP receptor protein. 
organisms that have been sequenced to date. One of the hypotheses for explaining the large genome size as well as the ubiquitous distribution of $P$. aeruginosa is based on the fact that this bacterium is able to metabolize various compounds as nutrients (Stover et al., 2000). Catabolism of nutrients involves a large number of genes for the uptake and catalysis of the particular nutrient. In the presence of a preferred carbon source, genes that are necessary for catabolism of less preferred carbon sources are repressed. This control mechanism has been designated catabolite repression control (for a review see Ullmann, 1996).

A homologue of the Escherichia coli global transcriptional regulator CRP (cAMP receptor protein) was identified in Pseudomonas aeruginosa and it was designated Vfr for virulence factor regulator due to its effect on the production of several virulence factors (West et al., 1994). Regulation of virulence factor production by $\mathrm{Vfr}$ is partially due to regulation of the las quorumsensing system by Vfr (Albus et al., 1997). The las quorum-sensing system in turn induces the $r h l$ quorumsensing system, and together the two quorum-sensing systems control expression of several genes for virulence factor production in P. aeruginosa (Pesci et al., 1997). However, Vfr also regulates expression of genes independent of the las and $r h l$ quorum-sensing systems. $V$ fr binds to the promoter of $\operatorname{tox} A$ and $\operatorname{reg} A$ to regulate the production of exotoxin $A$, thus demonstrating its direct role in the synthesis of this toxin (Runyen-Janecky et al., 1996).

$P$. aeruginosa $v f r$ encodes a 24225 Da polypeptide which is $67 \%$ identical and $91 \%$ similar to E. coli CRP (West et al., 1994). CRP regulates the expression of over 100 genes in E. coli, most notably the genes involved in carbon source utilization whose expression is subject to catabolite repression by glucose (Botsford \& Harman, 1992; Kolb et al., 1993; Ullmann \& Danchin, 1983). CRP functions by binding cAMP to form an active CRP-cAMP complex, which in turn binds to a specific sequence in the promoter of CRP-regulated genes.

Analysis of predicted amino acid sequences between the two proteins demonstrated that the majority of amino acid residues which constitute the structural features of CRP that are associated with cAMP binding, DNA binding and interaction with RNA polymerase are either identical or conserved in Vfr (West et al., 1994). The conservation of major functional domains between $\mathrm{Vfr}$ and CRP implies that these two proteins have similar functions in their respective organisms and may regulate similar pathways, including catabolite repression control. Previously, we found that the cloned $P$. aeruginosa $v f r$ gene could partially restore $\beta$-galactosidase activity in an E. coli crp mutant (West et al., 1994). In an E. coli crp cya mutant, which does not produce cAMP, exogenous cAMP was required for $\mathrm{Vfr}$ to restore $\beta$ galactosidase activity. Thus, these observations suggest that Vfr is mechanistically similar to CRP in regard to cAMP binding, recognition of CRP-binding sites and interaction with $E$. coli RNA polymerase.
In $P$. aeruginosa, the enzymes of several carbohydratetransport systems and catabolic pathways are subject to strong repression when acetate or tricarboxylic acid cycle intermediates are present in the growth medium along with the carbohydrate (for a review, see Collier $e t$ al., 1996). The repressible enzymes include enzymes belonging to the hex regulon (the central pathway of catabolism), the glucose transporter regulon, the mannitol utilization regulon and the fructose regulon. Thus for $P$. aeruginosa, preferred carbon sources are the tricarboxylic acid cycle intermediates, and non-preferred substrates include glucose, gluconate, glycerate, glycerol, fructose and mannitol. Additionally, intracellular cAMP levels in $P$. aeruginosa do not fluctuate in response to growth phase or to various carbon sources, including glucose, succinate, acetamide, histidine, lactate, acetate, gluconate and glycerol (Phillips \& Mulfinger, 1981; Siegel et al., 1977). This observation suggests that cAMP does not play a role in catabolite repression.

A global regulator of catabolite repression control (CRC) in $P$. aeruginosa has been cloned, designated as crc, and characterized (MacGregor et al., 1991). When $\mathrm{Crc}^{-}$mutants were grown in the presence of succinate, production of glucose-6-phosphate dehydrogenase, glucokinase, Entner-Doudoroff dehydratase, aldolase, amidase, and the enzymes involved in glucose and mannitol transport were not repressed (Wolff et al., 1991). The deduced amino acid sequence of the Crc protein showed that it was similar to a family of DNA repair enzymes composed of apurinic/apyrimidinic endonucleases (MacGregor et al., 1996). However, MacGregor et al. (1996) were not able to demonstrate in vitro nuclease or DNA-binding activity with purified Crc protein. Thus, the mechanism by which Crc controls catabolite repression in $P$. aeruginosa is still unclear.

As a part of our continuing effort to characterize the role of Vfr in P. aeruginosa physiology, in this study we addressed whether Vfr is a global regulator of gene expression and whether it has a role in catabolite repression control in this bacterium. We demonstrate that although Vfr is mechanistically similar to CRP of $E$. coli, its role in $P$. aeruginosa physiology differs from the role of CRP in E. coli.

\section{METHODS}

Bacterial strains, plasmids and growth conditions. Bacterial strains and plasmids used in this study are listed in Table 1 . All strains were routinely maintained on LB agar at $37^{\circ} \mathrm{C}$. For proteomic analysis, cells were grown to stationary phase in trypticase soy broth dialysate (TSBD) (Ohman et al., 1980) with aeration at $32{ }^{\circ} \mathrm{C}$ for $10 \mathrm{~h}$. For analysis of catabolite repression control, cells were grown in basal salts minimal (BSM) medium (Hylemon \& Phibbs, 1972) containing the appropriate carbon source $(40 \mathrm{mM}$ succinate or lactate) at $37^{\circ} \mathrm{C}$. Inducers were added as follows: $20 \mathrm{mM}$ mannitol for mannitol dehydrogenase and glucose-6-phosphate dehydrogenase, $20 \mathrm{mM}$ lactamide for amidase, and $0.2 \%(\mathrm{w} / \mathrm{v}) \mathrm{L}-$ histidine for urocanase. Cells were inoculated to Klett readings 
Table 1. Bacterial strains and plasmids

\begin{tabular}{|c|c|c|}
\hline Strain/plasmid & Genotype/phenotype* & Reference \\
\hline \multicolumn{3}{|l|}{ E. coli } \\
\hline RZ1330 & MG1655 rpsL $\Delta c r p l a c P 1^{+} i l v:: \operatorname{Tn} 10 \Delta c y a$ & $\begin{array}{l}\text { W. S. Reznikoff, } \\
\text { Dept of Biochemistry, } \\
\text { University of Wisconsin-Madison }\end{array}$ \\
\hline \multicolumn{3}{|l|}{ P. aeruginosa } \\
\hline PAO1 & Prototroph & Holloway et al. (1979) \\
\hline PAO8020 & PAO1 $\Delta c r c\left(3^{\prime}\right.$-end $) ; \mathrm{Tc}^{\mathrm{r}}$ & MacGregor et al. (1996) \\
\hline PAO9001 & PAO1 $\Delta$ ('orfX, $v f r, \operatorname{trp} C$ ') aacC1; $\mathrm{Gm}^{\mathrm{r}}$ & This study \\
\hline PAO9002 & PAO1 vfr101::aacC1; $\mathrm{Gm}^{\mathrm{r}}$ & This study \\
\hline \multicolumn{3}{|l|}{ Plasmids } \\
\hline pMMB66HE (EH) & tac promoter expression vector, $\operatorname{lacl}^{\mathrm{a}} ; \mathrm{Ap}^{\mathrm{r}}$ & Fürste et al. (1986) \\
\hline pRZ1306 & $\begin{array}{l}\text { pMMB66HE carrying promoterless } \mathrm{crp} \text { under the control of the tac } \\
\text { promoter; } \mathrm{Ap}^{\mathrm{r}}\end{array}$ & W. S. Reznikoff \\
\hline ptac917 & pMMB66EH carrying $v f r ; \mathrm{Ap}^{\mathrm{r}} / \mathrm{Cb}^{\mathrm{r}}$ & West et al. (1994) \\
\hline pWNP28 & $\begin{array}{l}\text { EcoRI-SmaI deletion of ptac } 917(v f r \text { promoter deleted so } v f r \text { is under the } \\
\text { control of the } t a c \text { promoter }) ; \mathrm{Ap}^{\mathrm{r}} / \mathrm{Cb}^{\mathrm{r}}\end{array}$ & This study \\
\hline pUCGM1 & pUC1918 carrying the aacC1 gene; $\mathrm{Gm}^{\mathrm{r}} \mathrm{Ap}^{\mathrm{r}}$ & Schweizer (1993) \\
\hline pNOT19 & pUC19 carrying a $10 \mathrm{bp} N d e \mathrm{I} /$ NotI adaptor in the NdeI site; Ap ${ }^{r}$ & Schweizer (1992) \\
\hline pWNP128 & $\begin{array}{l}\text { pNOT19 carrying a } 2.6 \mathrm{~kb} \text { SalI-Pst I fragment containing orfX, } v f r \text { and } \\
\operatorname{trpC} ; \mathrm{Ap}^{\mathrm{r}}\end{array}$ & This study \\
\hline pWNP129 & $\begin{array}{l}\mathrm{pWNP} 128 \text { with the } 1.2 \mathrm{~kb} \text { Xhol fragment carrying } v f r \text { replaced with the } \\
0.85 \mathrm{~kb} \text { Sall fragment carrying the aacC1 gene from pUCGM1; Gm }{ }^{\mathrm{r}} \mathrm{Ap}^{\mathrm{r}}\end{array}$ & This study \\
\hline pKF812 & pUCP18 carrying $v f r$ as a $1.2 \mathrm{~kb}$ XhoI fragment; $\mathrm{Ap}^{\mathrm{r}} / \mathrm{Cb}^{\mathrm{r}}$ & West et al. (1994) \\
\hline pWNP108 & pKF812 carrying the $v f r 101:: a a c C 1$ allele & This study \\
\hline pWNP109 & pUC18 carrying the $v$ fr $101::$ aacC1 allele & This study \\
\hline pUCP18 & Multi-copy E. coli-P. aeruginosa shuttle vector; $\mathrm{Ap}^{\mathrm{r}} / \mathrm{Cb}^{\mathrm{r}}$ & Schweizer (1991) \\
\hline
\end{tabular}

* $\mathrm{Gm}^{\mathrm{r}}$, gentamicin resistant; $\mathrm{Ap}^{\mathrm{r}}$, ampicillin resistant $\mathrm{Cb}^{\mathrm{r}}$, carbenicillin resistant; $\mathrm{Tc}^{\mathrm{r}}$, tetracycline resistant.

of 20-40 (no. 66 red filter) from plates containing BSM agar with $40 \mathrm{mM}$ succinate and the appropriate antibiotics and grown to Klett readings of 150-210 (mid- to late-exponential). For PAO9001, tryptophan was included at $2 \mathrm{mM}$ final concentration. Antibiotics were used at the following concentrations per $\mathrm{ml}$ : for $P$. aeruginosa, $250 \mu \mathrm{g}$ carbenicillin, $50 \mu \mathrm{g}$ tetracycline and $50 \mu \mathrm{g}$ gentamicin; for E. coli, $100 \mu \mathrm{g}$ ampicillin and $15 \mu \mathrm{g}$ gentamicin.

Construction of vfr null mutants. The $v f r$ deletion mutant PAO9001 and the $v f r$ insertion mutant PAO9002 were constructed by allelic exchange. For construction of PAO9001, a $2.6 \mathrm{~kb}$ SalI-PstI DNA fragment containing $v f r$ and flanking DNA was cloned into pNOT19 to generate pWNP128. A $1 \cdot 2 \mathrm{~kb}$ Xhol fragment containing $v f r$ was deleted from pWNP128 and was replaced with a $0.85 \mathrm{~kb}$ SalI fragment containing the gentamicin-resistance cassette from pUCGM1 to generate pWNP129. This cassette contains the aacC1 gene encoding gentamicin acetyltransferase-3-1 $\left(\mathrm{Gm}^{\mathrm{r}}\right)$. For PAO9002, the $0 \cdot 85 \mathrm{~kb} S m a \mathrm{I}$ fragment containing the gentamicin-resistance cassette from pUCGM1 was inserted into the unique $S p h$ I site (blunt-ended with mung bean nuclease) of $v \mathrm{fr}$ on pKF812 to generate pWNP108. The $v$ fr101::aacC1 allele with the gentamicin-resistance cassette was excised from pWNP108 as an EcoRI-HindIII fragment and ligated into pUC18 to generate $\mathrm{pWNP109}$. pWNP129 and pWNP109 were introduced into PAO1 by electroporation. Since the ColE1- derived vectors are not maintained in $P$. aeruginosa, stable gentamicin-resistant colonies can only be obtained if the plasmid has integrated into the chromosome. Recombinants were selected on media containing gentamicin $\left(50 \mu \mathrm{g} \mathrm{ml}^{-1}\right)$ and were screened for loss of vector sequences by sensitivity to carbenicillin. Southern analysis of chromosomal DNA from the gentamicin-resistant, carbenicillin-sensitive recombinants confirmed that the $1.2 \mathrm{~kb}$ Xhol fragment carrying $v f r$ was deleted from the chromosome and replaced with the aacC1 gene for PAO9001 and that the vfr101:aacC1 mutant allele replaced the $v f r$ gene for PAO9002 (data not shown).

Two-dimensional electrophoretic analysis. Cells were grown in TSBD for $10 \mathrm{~h}\left(2 \mathrm{~h}\right.$ into stationary phase) at $37^{\circ} \mathrm{C}$ with aeration, harvested, and resuspended in $10 \mathrm{mM}$ HEPES, $\mathrm{pH} 7 \cdot 2,5 \mathrm{mM}$ EDTA and $1 \mathrm{mM}$ PMSF. Cells were again harvested by centrifugation ( $15000 \boldsymbol{g}$ for $5 \mathrm{~min}$ ), resuspended in SDS boiling buffer $(5 \%$ SDS, $10 \%, \mathrm{v} / \mathrm{v}$, glycerol and $60 \mathrm{mM}$ Tris/ $\mathrm{HCl}, \mathrm{pH} 6 \cdot 8$ ), and boiled for $5 \mathrm{~min}$. The insoluble particulate material was removed by centrifugation for $5 \mathrm{~min}$ at $15000 \mathrm{~g}$. Protein concentration was determined via the BCA method (Smith et al., 1985), and $\beta$-mercaptoethanol was added to the samples at a final concentration of $5 \%$. Approx. $30 \mu \mathrm{g}$ protein was used to analyse the protein profiles between $\mathrm{pI}$ 4-8.5 and molecular mass $14-220 \mathrm{kDa}$ via two-dimensional gel electrophoresis. The electrophoresis was performed by the Kendrick Laboratories, Inc. (Madison, WI), and the protein spots were visualized by silver staining. 
Purification of CRP and Vfr. CRP and Vfr were purified from crude cell lysates of E. coli RZ1330/pRZ1306 or P. aeruginosa PA103/pWNP28, respectively, by affinity chromatography on cAMP-agarose as described by Ghosaini et al. (1988) with the following modifications. To overexpress CRP or Vfr, IPTG (1 $\mathrm{mM}$ final concentration) was added to 5-litre mid-exponential-phase cultures of RZ1330/pRZ1306 or PA103/pWNP28 respectively, grown in LB. E. coli RZ1330/pRZ1306 was harvested $15 \mathrm{~h}$ after induction and P. aeruginosa PA103/ pWNP28 was harvested $6 \mathrm{~h}$ after induction by centrifugation for $15 \mathrm{~min}$ at $5000 \mathrm{~g}$. To prepare crude cell lysates, the cell pellets were resuspended in $100 \mathrm{mM}$ Tris $/ \mathrm{HCl}, \mathrm{pH} 8.0,50 \mathrm{mM}$ $\mathrm{KCl}, 2 \mathrm{mM}$ EDTA, $5 \mathrm{mM} \beta$-mercaptoethanol, $1 \mathrm{mM}$ sodium azide and $200 \mu \mathrm{g}$ lysozyme $\mathrm{ml}^{-1}$ and incubated at $25^{\circ} \mathrm{C}$ for $20 \mathrm{~min}$. The solution was adjusted to $25 \mathrm{mM}$ Tris $/ \mathrm{HCl}, \mathrm{pH}$ $8 \cdot 0,25 \mathrm{mM} \mathrm{MgSO}_{4}$ and $1 \%$ BRIJ 35, and the lysates were incubated at $4{ }^{\circ} \mathrm{C}$ for $10 \mathrm{~min}$. To decrease the viscosity due to nucleic acids, the lysate was sonicated at approx. $100 \mathrm{~W}$ for three $10 \mathrm{~s}$ intervals on ice using a Vibra Cell sonicator (Sonics and Materials). The cell-free extract was obtained by centrifugation at $16000 \mathrm{~g}$ for $30 \mathrm{~min}$ at $4{ }^{\circ} \mathrm{C}$ and was applied to a $5 \mathrm{ml} \mathrm{cAMP-agarose}$ column (Sigma) as described by Ghosaini et al. (1988).

cAMP-binding assay. This assay was performed by the ammonium sulfate precipitation method developed by Emmer et al. (1970) with slight modifications. Briefly, the assay was performed in $10 \mathrm{mM}$ potasssium phosphate, $\mathrm{pH} 7 \cdot 4$, with the protein, $\left[8-^{3} \mathrm{H}\right]$ adenosine $3^{\prime}, 5^{\prime}$-cyclic phosphate (cAMP, $25 \mathrm{Ci} \mathrm{mmol}^{-1}, 925 \mathrm{GBq} \mathrm{mmol}^{-1}$; Amersham), and a carrier protein, casein $(200 \mu \mathrm{g})$, in a total volume of $100 \mu \mathrm{l}$. After a $5 \mathrm{~min}$ incubation at $0-1{ }^{\circ} \mathrm{C}, 400 \mu \mathrm{l}$ ice-cold saturated $\left(\mathrm{NH}_{4}\right)_{2} \mathrm{SO}_{4}$ was added and the protein-cAMP complex was allowed to precipitate for $5 \mathrm{~min}$ on ice. The precipitate was collected by centrifugation in a microcentrifuge and the pellet was resuspended in $500 \mu \mathrm{l}$ double-distilled $\mathrm{H}_{2} \mathrm{O}$. The resuspended pellet was transferred to a scintillation vial containing $10 \mathrm{ml}$ Opti-fluor (Packard) and the radioactivity was quantified in a Packard Tri-Carb 4530 scintillation counter. The control reaction contained all of the assay components except for the protein; therefore, the amount of $\left[{ }^{3} \mathrm{H}\right] \mathrm{cAMP}$ bound specifically to the enzyme was determined by subtracting the level of nonspecific binding in the control reaction from the total level of radioactivity in the assay reaction. The saturation in cAMP binding was achieved by increasing the quantity of $\left[{ }^{3} \mathrm{H}\right] \mathrm{cAMP}$ added to the assay. Approx. $0 \cdot 3 \mu \mathrm{g}$ CRP and $1 \cdot 1 \mu \mathrm{g}$ $\mathrm{Vfr}$ was used in the assays to determine the apparent dissociation constants for cAMP.

Gel retardation assays. A DNA fragment containing the lacZ promoter was isolated from pUCP19 as a 231 bp PvuIIHindIII DNA fragment and was end-labelled with $[\alpha-$ ${ }^{32} \mathrm{P}$ ]dNTP using DNA polymerase Klenow fragment (United States Biochemical). The binding reactions, containing approximately $40 \mathrm{pM}$ DNA and various concentrations of either purified Vfr or CRP, were carried out at room temperature for $20 \mathrm{~min}$ in $10 \mathrm{mM}$ Tris/ $\mathrm{HCl} \mathrm{pH} \mathrm{7.4,} 100 \mathrm{mM} \mathrm{KCl}, 1 \mathrm{mM}$ EDTA, $5 \%(\mathrm{v} / \mathrm{v})$ glycerol, $1 \mathrm{mM} \mathrm{DTT}, 50 \mu \mathrm{g} \mathrm{BSA} \mathrm{ml} \mathrm{m}^{-1}$ and $20 \mu \mathrm{M}$ cAMP as described by DeVault et al. (1991), and were then electrophoresed on a $6 \%$ native polyacrylamide gel in $10 \mathrm{mM}$ Tris/ $\mathrm{HCl} \mathrm{pH} \mathrm{7•4,} 1 \mathrm{mM}$ EDTA and $20 \mu \mathrm{M}$ cAMP for $1.5 \mathrm{~h}$ at $10 \mathrm{~V} \mathrm{~cm}^{-1}$. The gel was dried and exposed to Kodak XOMAT AR5 film at $-70{ }^{\circ} \mathrm{C}$ overnight with an intensifying screen.

Enzyme assays. Cells were disrupted by resuspending frozen cell pellets (from $30 \mathrm{ml}$ cultures) in $2.5 \mathrm{ml} 50 \mathrm{mM}$ Tris/ $\mathrm{HCl}$ $\mathrm{pH} 8.0$ and pressing through a French pressure cell at
16000 p.s.i. (110 MPa). S-180 extracts were obtained after centrifugation at $180000 \mathrm{~g}$ for $30 \mathrm{~min}$. The following enzyme assays were done as previously described: glucose-6-phosphate dehydrogenase (Hylemon \& Phibbs, 1972), mannitol dehydrogenase (Siegel et al., 1977), urocanase (Lessie \& Neidhardt, 1967), except that urocanate was used at $50 \mu \mathrm{M}$, and amidase (Brammar \& Clarke, 1964). Glucose-6-phosphate dehydrogenase and mannitol dehydrogenase were assayed at $25^{\circ} \mathrm{C}$, while urocanase and amidase assays were at $37^{\circ} \mathrm{C}$. Amidase assays were done on cell suspensions; other enzyme assays were done on S-180 extracts. For the determination of specific activities, units refer to $\mu \mathrm{mol}$ product $\mathrm{min}^{-1}$. Protein concentrations were assayed relative to BSA standards by the Lowry method. For cell suspensions, total protein was first precipitated with trichloroacetic acid prior to the protein determination.

\section{RESULTS}

\section{Construction of vfr null mutants}

To assess the effect of a $v f r$ mutation on $P$. aeruginosa physiology, we constructed two $v f r$ null mutants: a complete $v f r$ deletion mutant and a $v f r$ insertion mutant. The deletion mutant (PAO9001) was constructed by replacing a $1.2 \mathrm{~kb}$ deleted DNA fragment that carried $v f r$ as well as portions of an ORF upstream of $v f r(o r f X)$ (Runyen-Janecky et al., 1997) and a portion of trpC gene that is located directly downstream of $v f r$, with the aac $\mathrm{C} 1$ gene that encodes gentamicin resistance. The insertion mutant (PAO9002) was constructed by inserting the aacC1 gene into the unique SphI site of $v f r$. The mutant alleles were introduced into the $P$. aeruginosa wild-type strain PAO1 and the inheritance of $v f r$ mutant alleles via allelic exchange was selected and screened as described in Methods. Within the scope of this study, both the deletion mutant and the insertion mutant behaved similarly, and thus indicated that deletion of orf $X$ or $\operatorname{trp} C$ did not have a demonstrable effect on $\mathrm{Vfr}$ function.

\section{Proteome analysis of a vfr101::aacC1 mutant}

A proteome analysis was performed to assess whether Vfr is a global regulator of gene expression in $P$. aeruginosa. As shown in Fig. 1, comparison of the silverstained two-dimensional polyacrylamide gel electrophoresis patterns between the wild-type strain (PAO1) and the isogenic $v$ fr101::aacC1 null mutant (PAO9002) revealed that a null mutation in $v f r$ resulted in altered production of numerous proteins. We found that at least 43 protein spots were either absent or significantly decreased in the proteome pattern of the $v f r$ mutant when compared to that of the parent strain (Fig. 1, upper panel). This confirmed our hypothesis that Vfr acts as a positive regulator of gene expression in $P$. aeruginosa and that Vfr induces the expression of many genes. In contrast, we also found that production of 17 protein spots appeared to be repressed by the presence of $\mathrm{Vfr}$ (Fig. 1, lower panel). Thus, Vfr is a global regulator of gene expression in P. aeruginosa that has either a positive or negative effect on expression of at least 60 genes. 

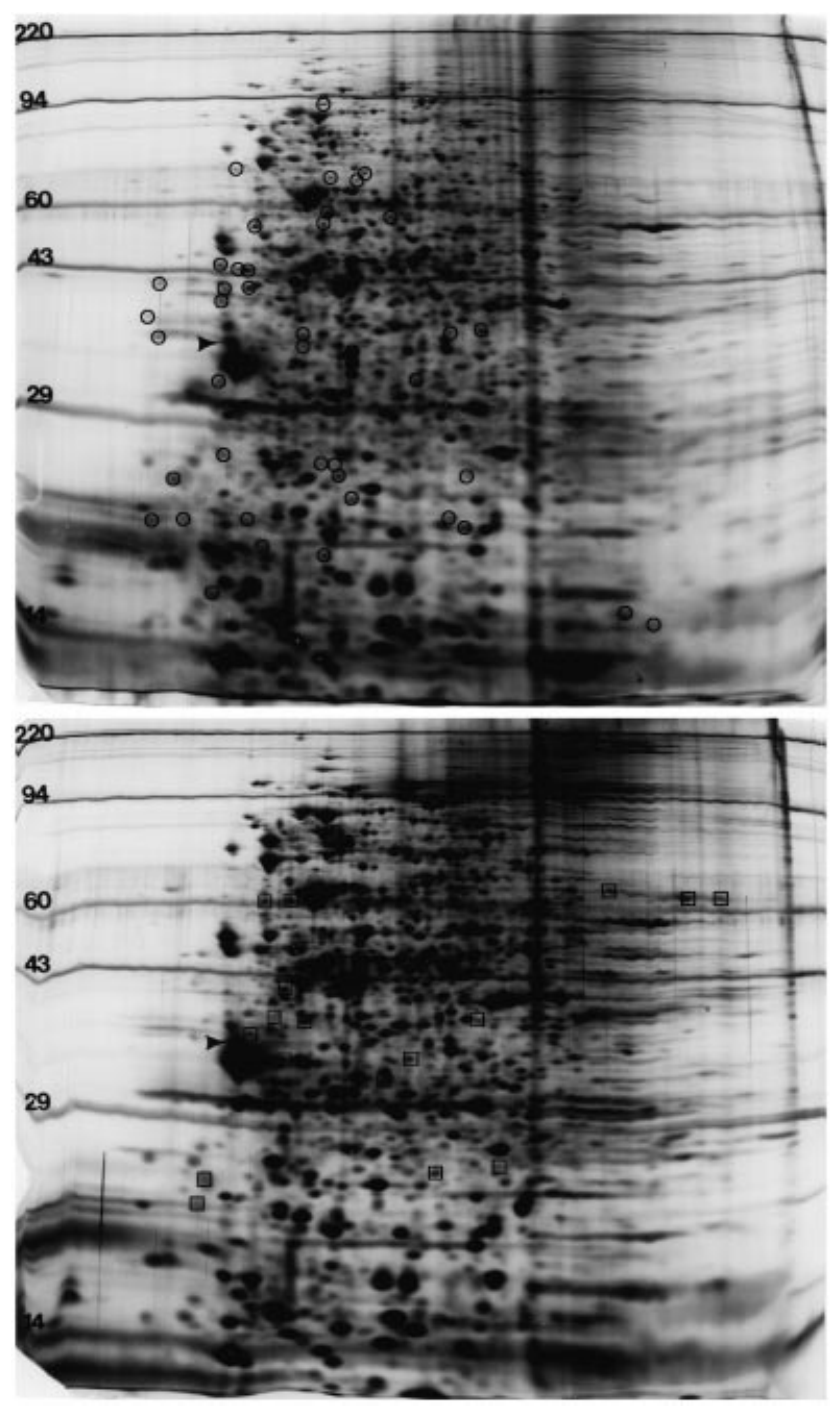

Fig. 1. Two-dimensional electrophoretic analysis showing the effect of vfr101 mutation on overall protein synthesis in $P$. aeruginosa. PAO1 and its vfr mutant (PA09002) were grown in TSBD into the late stationary phase of growth $(10 \mathrm{~h})$. Cells were harvested and total cellular proteins were separated by two-dimensional gel electrophoresis. Proteins were visualized by silver staining. The arrow indicates the single isoelectric focusing standard tropomyosin, which has a pl of 5.2 and a molecular mass of $33 \mathrm{kDa}$. Upper panel: PAO1. Circles indicate protein spots that are missing or reduced in the vfr mutant. Lower panel: PA09002. Squares indicate protein spots that are missing or reduced in the parent strain.

\section{Vfr binding to the $E$. coli lacZ promoter requires CAMP}

In E. coli, expression of the lacZ gene, encoding $\beta$ galactosidase, requires the binding of the CRP-cAMP complex to the palindromic CRP-binding sequence in the lac promoter. The observation that $P$. aeruginosa Vfr can replace CRP to activate $\beta$-galactosidase production in E. coli suggested that, like CRP, Vfr binds the lac promoter (West et al., 1994). To further test this hypothesis, we used gel retardation assays to examine

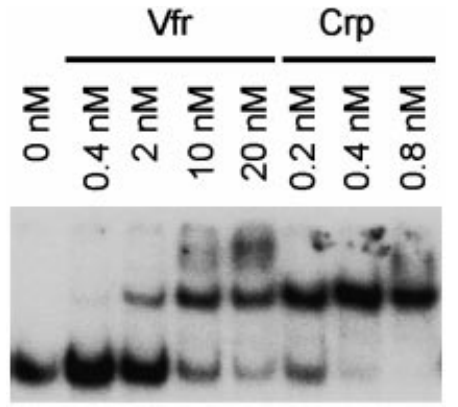

Fig. 2. Binding of $\mathrm{Vfr}$ and $C R P$ to the lacZ promoter. $A$ radiolabelled Pvull-HindIII DNA fragment containing the lacZ promoter from pUCP19 was incubated with purified $\mathrm{Vfr}$ or CRP as described in Methods. The first lane contained lacZ promoter DNA without any protein. Subsequent lanes contained increasing concentrations of either Vfr or CRP as indicated.

the ability of Vfr to bind the lac promoter. Both $P$. aeruginosa $\mathrm{Vfr}$ and E. coli CRP retarded the mobility of a DNA fragment that contains the lac promoter (Fig. 2). The addition of excess unlabelled lac promoter DNA, but not unlabelled nonspecific DNA, prevented Vfr from binding to the labelled lac promoter DNA fragment (data not shown). Additionally, when cAMP was not present in the reaction buffer, neither Vfr nor CRP bound the lac promoter DNA fragment (data not shown). These results confirm the previously demonstrated genetic evidence that Vfr complements an E. coli crp mutant for $\beta$-galactosidase production and that this complementation requires cAMP. Thus, the formation of a Vfr-cAMP complex is required for specific binding of the protein to the lac promoter, and therefore, the Vfr-cAMP complex should function in a mechanistically similar way to the CRP-cAMP complex. However, we note that a much higher concentration of Vfr than CRP was needed to bind and shift the lacZ promoter (Fig. 2). This result supports the earlier observation that Vfr partially complements the E. coli crp mutant, and it may indicate a difference in DNA sequence specificity of binding sites for the two proteins.

\section{CAMP-binding properties of Vfr and CRP}

To evaluate the specificity of the Vfr-cAMP interaction, we determined the apparent dissociation constants $\left(K_{\mathrm{d}}\right)$ of Vfr and CRP for this nucleotide. The data from the cAMP-binding experiments were analysed with the nonlinear regression data analysis program Enzfitter (Elsevier-Biosoft). The apparent $K_{\mathrm{d}}$ values were $0.4 \mu \mathrm{M}$ for CRP and $1.6 \mu \mathrm{M}$ for Vfr binding to cAMP (data not shown). Similar apparent $K_{\mathrm{d}}$ values were obtained by the competitive binding assay using non-radioactive cAMP as the competitor substrate (data not shown). The apparent $K_{\mathrm{d}}$ obtained for CRP agrees with the values of $1 \mu \mathrm{M}$ and 3-4 $\mu \mathrm{M}$ reported for CRP isolated from E. coli and Vibrio harveyi, respectively (Chen et al., 1985; Emmer et al., 1970). The observation that the apparent $K_{\mathrm{d}}$ of $\mathrm{Vfr}$ for cAMP falls within the same range as $K_{\mathrm{d}}$ values reported for CRP from E. coli and $V$. 
Table 2. Catabolite repression control is not affected by vfr null mutations

Strains were grown in basal salts medium supplemented with either succinate, a strong repressor of inducible catabolite operons, or lactate, a weak repressor of inducible catabolite operons. Metabolic enzyme synthesis was induced by addition of lactamide for amidase, mannitol for mannitol dehydrogenase and glucose-6-phosphate dehydrogenase, and histidine for urocanase. Amidase assays were done in triplicate, and all other assays in duplicate. Standard deviations are shown in parentheses.

\begin{tabular}{|c|c|c|c|c|c|c|c|c|}
\hline \multirow[t]{3}{*}{ Strain } & \multicolumn{2}{|c|}{$\begin{array}{l}\text { Amidase } \\
\left(\mathrm{IU} \mathbf{~ m g}^{-1}\right)\end{array}$} & \multirow{2}{*}{\multicolumn{2}{|c|}{$\begin{array}{c}\text { Mannitol } \\
\text { dehydrogenase } \\
\left(\mathbf{m I U ~ m g}^{-1}\right)\end{array}$}} & \multirow{2}{*}{\multicolumn{2}{|c|}{ 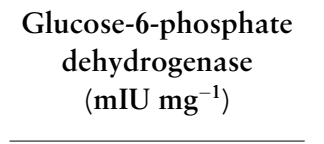 }} & \multicolumn{2}{|c|}{$\begin{array}{l}\text { Urocanase } \\
\left(\mathrm{mIU} \mathrm{mg}^{-1}\right)\end{array}$} \\
\hline & \multirow{2}{*}{ Succinate } & \multirow{2}{*}{ Lactate } & & & & & Succinate & Lactate \\
\hline & & & Succinate & Lactate & Succinate & Lactate & & \\
\hline PAO1 $\left(\mathrm{Vfr}^{+}\right)$ & $0.5(0 \cdot 2)$ & $14 \cdot 8(0 \cdot 3)$ & $2 \cdot 4(0 \cdot 2)$ & $36(0 \cdot 2)$ & $8(1 \cdot 3)$ & $137(7 \cdot 0)$ & $3 \cdot 7(4 \cdot 0)$ & $40(5 \cdot 4)$ \\
\hline PAO9001 $\left(\mathrm{Vfr}^{-}\right)$ & $0 \cdot 4(0 \cdot 1)$ & $9 \cdot 5(0.6)$ & $1 \cdot 2(0 \cdot 4)$ & $29(0 \cdot 8)$ & $5(0 \cdot 6)$ & $108(15)$ & $1 \cdot 0(1 \cdot 3)$ & $25(0 \cdot 4)$ \\
\hline PAO9002 $\left(\mathrm{Vfr}^{-}\right)$ & $0 \cdot 6(0 \cdot 1)$ & $10 \cdot 6(0 \cdot 8)$ & $1 \cdot 4(0 \cdot 2)$ & $40(0 \cdot 5)$ & $8(1 \cdot 0)$ & $140(3 \cdot 3)$ & $2 \cdot 1(0 \cdot 8)$ & $42(1 \cdot 1)$ \\
\hline
\end{tabular}

Table 3. vfr does not complement a crc mutant for succinate mediated catabolite repression

Strains were grown in basal salts medium supplemented with succinate, and metabolic enzyme synthesis was induced by the addition of lactamide for amidase or mannitol for mannitol dehydrogenase and glucose-6-phosphate dehydrogenase. All assays were done in duplicate. Standard deviations are shown in parentheses.

\begin{tabular}{|llcc|}
\hline Strain & $\begin{array}{c}\text { Amidase } \\
\left(\mathbf{I U ~ m g ~}^{-1}\right)\end{array}$ & $\begin{array}{c}\text { Mannitol } \\
\text { dehydrogenase } \\
\left(\mathbf{m I U ~ m g}^{-1}\right)\end{array}$ & $\begin{array}{c}\text { Glucose-6-phosphate } \\
\text { dehydrogenase } \\
\left(\mathbf{m I U ~ m}^{-1}\right)\end{array}$ \\
\hline PAO1 & $0 \cdot 3(0 \cdot 1)$ & $2 \cdot 5(1 \cdot 6)$ & $2 \cdot 7(0 \cdot 8)$ \\
PAO1/pUCP18 & $0 \cdot 3(0 \cdot 05)$ & $3 \cdot 5(0 \cdot 4)$ & $3 \cdot 2(0 \cdot 2)$ \\
PAO1/pKF812 & $0 \cdot 2(0 \cdot 02)$ & $2 \cdot 0(0 \cdot 5)$ & $3 \cdot 7(0 \cdot 1)$ \\
PAO8020 & $1 \cdot 6(0 \cdot 5)$ & $22(0 \cdot 8)$ & $21(4 \cdot 0)$ \\
PAO8020/pUCP18 & $1 \cdot 3(0 \cdot 1)$ & $26(0 \cdot 1)$ & $18(3 \cdot 5)$ \\
PAO8020/pKF812 & $2 \cdot 3(0 \cdot 5)$ & $23(1 \cdot 8)$ & $15(0 \cdot 5)$ \\
\hline
\end{tabular}

harveyi suggests that these two proteins bind cAMP with a similar affinity.

\section{Vfr is not required for catabolite repression control in $P$. aeruginosa}

Since Vfr can function as a positive regulator of catabolite repression by substituting for the cAMP receptor in E. coli, $\mathrm{Vfr}$ may fulfil a similar role in catabolite repression control in $P$. aeruginosa. To examine this possibility, we determined whether catabolite repression control occurred in two $v f r$ null mutants of PAO1. The parental strain PAO1 and the $v f r$ null mutants, PAO9001 and PAO9002, were grown in basal salts medium that was supplemented with either succinate, a strong repressor of inducible catabolic operons, or lactate, a weak repressor of inducible catabolic operons, as sole carbon sources. Metabolic enzyme synthesis was induced by the addition of lactamide for amidase, mannitol for mannitol dehydrogenase and glucose-6-phosphate dehydrogenase, and histidine for urocanase. In both PAO1 and the $v f r$ null mutants PAO9001 and PAO9002, the presence of succinate in the growth medium repressed the synthesis of amidase, mannitol dehydrogenase, glucose-6-phosphate dehydrogenase and urocanase (Table 2). Based on these results, $\mathrm{Vfr}$ does not appear to be required for catabolite repression control in $P$. aeruginosa.

In $P$. aeruginosa crc mutants, catabolite-repressible genes are no longer repressed in the presence of preferred carbon sources such as succinate (Wolff et al., 1991). To confirm that $\mathrm{Vfr}$ has no role in catabolite repression, we assayed whether Vfr could complement a $P$. aeruginosa crc mutant. The bacteria were grown in basal salts medium containing succinate to elicit catabolite repression. Metabolic enzyme synthesis was induced by the addition of lactamide for amidase or mannitol for mannitol dehydrogenase and glucose-6-phosphate dehydrogenase. The $\operatorname{crc}$ mutant PAO8020 carrying either the vector control (pUCP18) or the cloned $v f r$ gene (pKF812) failed to repress the synthesis of amidase, mannitol dehydrogenase or glucose-6-phosphate dehydrogenase in the presence of succinate (Table 3 ). Thus, the function of Crc could not be replaced by multiple copies of $\mathrm{Vfr}$ and the results confirmed that $\mathrm{Vfr}$ is not 
required for the catabolite repression response in $P$. aeruginosa.

\section{DISCUSSION}

The results of this study support our hypothesis that Vfr is a global regulator of gene expression in $P$. aeruginosa. Based on our limited proteome analysis, it appears that Vfr both activates and represses the production of numerous proteins in $P$. aeruginosa. Since Vfr regulates the quorum-sensing systems las and rhl (Albus et al., 1997), it is possible that Vfr indirectly regulates production of many of the proteins via the quorum-sensing systems. Studies to identify genes that are directly regulated by Vfr are currently in progress.

We are also interested in elucidating the mechanism of $V$ fr function in $P$. aeruginosa. The requirement of cAMP for Vfr binding to the E. coli lac promoter further enhances our hypothesis that Vfr uses a similar molecular mechanism as CRP of E. coli (i.e. formation of a complex with cAMP and binding to a specific CRPbinding sequence) to activate transcription in E. coli. We found that Vfr bound cAMP with an apparent dissociation constant $\left(K_{\mathrm{d}}\right)$ of $1.6 \mu \mathrm{M}$, which was similar to the apparent $K_{\mathrm{d}}$ of CRP. The similar binding constant implies that, like CRP, Vfr activity should be sensitive to fluctuations in the cAMP levels. We previously demonstrated that Vfr-dependent activation of $\beta$-galactosidase production in E. coli could be repressed in the presence of glucose (West et al., 1994). Based on our data showing that Vfr binds cAMP with a similar dissociation constant as CRP, we propose that, as with CRP, glucose repression of $\mathrm{Vfr}$-dependent $\beta$-galactosidase production in E. coli is a direct result of decreased cAMP levels. Thus, our data suggest that in E. coli Vfr functions in a manner mechanistically similar to CRP. However, in $P$. aeruginosa, it is not clear that cAMP is the only ligand which binds to and activates Vfr. cAMP levels remain constant and do not change in response to various carbon sources (Phillips \& Mulfinger, 1981; Siegel et al., 1977), suggesting that it may not function as a modulator of Vfr activity. A role for cAMP has not been established in $P$. aeruginosa. Additionally, even though there is a high degree of similarity between Vfr and CRP, the greatest variability between these two proteins occurs in the cAMP-binding domain (West et al., 1994). Additional work is needed to determine if cAMP is the only ligand required for $\mathrm{Vfr}$ activity.

In contrast to the ability of Vfr to mediate catabolite repression control in E. coli, Vfr does not function in catabolite repression control in $P$. aeruginosa. Based on the differences in metabolic capabilities of $P$. aeruginosa and E. coli, it was not surprising that the $P$. aeruginosa catabolite repression control system did not require Vfr. First, the carbon source preference is very different between the two bacteria: while E. coli prefers a carbohydrate such as glucose $P$. aeruginosa prefers an organic acid such as succinate. Second, many of the genes that are catabolite repressed in $P$. aeruginosa, such as those encoding amidase and mannitol dehydrogenase, are not found in E. coli, and therefore it is reasonable to suppose that a catabolite repression system other than a CRP-cAMP-like mechanism may control their expression. In addition, $\mathrm{Vfr}$ does not appear to regulate genes in $P$. aeruginosa that are regulated by CRP in enterobacteria. For example, CRP is required for the production of succinate dehydrogenase in E. coli (Wood $e t$ al., 1984) and urocanase in Klebsiella aerogenes ( $K$. pneumoniae) (Nieuwkoop et al., 1984). These enzymes permit growth of these bacteria on succinate and histidine, respectively, as sole carbon sources. However, the $P$. aeruginosa PAO1 $v f r$ insertion mutant PAO9002 was able to grow with either succinate or histidine as a sole carbon source (L. J. Runyen-Janecky, unpublished results). Furthermore, the $v f r$ null mutants PAO9001 and PAO9002 produced a similar amount of urocanase as the parent strain. Finally, a Vfr-cAMP complex would be a poor candidate for mediating catabolite repression in response to various carbon sources, since cAMP levels are constant in $P$. aeruginosa (Phillips \& Mulfinger, 1981; Siegel et al., 1977).

In addition to $P$. aeruginosa $\mathrm{Vfr}$, homologues of the $E$. coli CRP protein have been identified in numerous physiologically and ecologically distinct members of the gamma subdivision of the purple eubacteria including Salmonella enterica Serovar Typhimurium, Vibrio fischeri, V. harveyi and Shigella flexneri, members of the Enterobacteriaceae family; Haemophilus influenzae, a member of the Pasturellaceae family; and Xanthomonas campestris, a member of the Pseudomonadaceae family (Chandler, 1992; Cossart et al., 1986; DeCrecy-Lagard et al., 1990). Among these species, the members of the Enterobacteriaceae family (E. coli, Salmonella enterica and Shigella flexneri) are the most closely related, while $X$. campestris and $P$. aeruginosa are more distantly related to the Enterobacteriaceae family and also only distantly related to each other (Woese et al., 1985). The presence of CRP in such a diverse group of bacteria suggests that CRP was present in the common ancestor of these species. Although the structure of a CRP homologue remained conserved as members of the gamma subdivision of the purple eubacteria evolved from this common ancestor, the cellular role of this protein did not. For instance, Vfr does not appear to play a role in catabolite repression in $P$. aeruginosa, and the genes identified thus far that are members of the Vfr regulon are secreted virulence determinants or regulators of secreted virulence determinants (Albus et al., 1997; Maleniak et al., 1996; West et al., 1994). Likewise, the X. campestris CRP homologue, CLP, does not regulate metabolism but instead regulates phytopathogenicity (DeCrecy-Lagard et al., 1990). In H. influenzae, CRP regulates development of competence for transformation (Chandler, 1992). The evolution of diverse roles of the CRP homologues in various species may reflect the different physiological needs of each species.

In conclusion, this report demonstrates that although $\mathrm{Vfr}$, the $P$. aeruginosa CRP homologue, can function as a component of catabolite repression control in E. coli, $\mathrm{Vfr}$ is not required for catabolite repression in $P$. 
aeruginosa. Although Vfr and CRP are both global transcriptional activators, their specific roles appear to have evolved to suit the particular needs of each species that are influenced by their natural niches and physiologies. Thus, it is not surprising that different sets of genes have evolved as members of the CRP/Vfr regulon in E. coli and P. aeruginosa. The corollary to this is that functions that are under the control of the CRP/Vfr regulon in one species may be part of a different regulon in another species, as seems to be the case for catabolite repression. Future study of identification of Vfr-regulated genes will help elucidate the function of this regulator on the physiology of $P$. aeruginosa.

\section{ACKNOWLEDGEMENTS}

This work was supported by Public Health Service Grant AI31477 from the National Institute of Allergy and Infectious Diseases awarded to S.E.H.W, and by the East Carolina University School of Medicine Biotechnology Program. S.-J. Suh was supported by the Cystic Fibrosis Foundation postdoctoral fellowship SUH96F0. L. J.R.-J. was a trainee under Public Health Service grant T32 GM 07215. We thank Dr W. Hendrickson for discussions concerning the purification of Vfr and Dr Laura Silo-Suh for critical reading of the manuscript.

\section{REFERENCES}

Albus, A. M., Pesci, E. C., Runyen-Janecky, L. J., West, S. E. H. \& Iglewski, B. H. (1997). Vfr controls quorum sensing in Pseudomonas aeruginosa. J Bacteriol 179, 3928-3935.

Botsford, J. L. \& Harman, J. G. (1992). Cyclic AMP in prokaryotes. Microbiol Rev 56, 100-122.

Brammar, W. J. \& Clarke, P. H. (1964). Induction and repression of Pseudomonas aeruginosa amidase. J Gen Microbiol 37, 307-319.

Chandler, M. S. (1992). The gene encoding cAMP receptor protein is required for competence development in Haemophilus influenzae Rd. Proc Natl Acad Sci U S A 89, 1626-1630.

Chen, P.-F., Tu, S.-C., Hagag, N., Wu, F. Y.-H. \& Wu, C.-W. (1985). Isolation and characterization of a cyclic AMP receptor protein from luminous Vibrio harveyi cells. Arch Biochem Biophys 941, 425-431.

Collier, D. N., Hager, P. W. \& Phibbs, P. V., Jr (1996). Catabolite repression control in the pseudomonads. Res Microbiol 147, 551-561.

Cossart, P., Groisman, E. A., Serre, M.-C., Casadaban, M. J. \& Gicquel-Sanzey, B. (1986). crp genes of Shigella flexneri, Salmonella typhimurium, and Escherichia coli. J Bacteriol 167, 639-646.

DeCrecy-Lagard, V., Glaser, P., Lejeune, P., Sismeiro, O., Barber, C. E., Daniels, M. J. \& Danchin, A. (1990). A Xanthomonas campestris pv. campestris protein similar to catabolite activation factor is involved in regulation of phytopathogenicity. J Bacteriol 172, 5877-5883.

DeVault, J. D., Hendrickson, W., Kato, J. \& Chakrabarty, A. M. (1991). Environmentally regulated $a l g D$ promoter is responsive to the cAMP receptor protein in Escherichia coli. Mol Microbiol 5, 2503-2509.

Emmer, M., deCrombrugghe, B., Pastan, I. \& Perlman, R. (1970). Cyclic AMP receptor protein of E. coli: its role in the synthesis of inducible enzymes. Proc Natl Acad Sci US A 66, 480-487.
Fürste, J. P., Pansegrau, W., Frank, R., Blöcker, H., Scholz, P. \& Bagdasarian, M. (1986). Molecular cloning of the plasmid RP4 primase region in a multi-host-range $t a c P$ expression vector. Gene 48, 119-131.

Ghosaini, L. R., Brown, A. M. \& Sturtevant, J. M. (1988). Scanning calorimetric study of the thermal unfolding of catabolic activator protein from Escherichia coli in the absence and presence of cyclic mononucleotides. Biochemistry 27, 5257-5261.

Holloway, B. W., Krishnapillai, V. \& Morgan, A. F. (1979). Chromosomal genetics of Pseudomonas. Microbiol Rev 43, 73-102.

Hylemon, P. B. \& Phibbs, P. V., Jr (1972). Independent regulation of hexose catabolizing enzymes and glucose transport activity in Pseudomonas aeruginosa. Biochem Biophys Res Commun 48, 1041-1048.

Kolb, A., Busby, S., Buc, H., Garges, S. \& Adhya, A. (1993). Transcriptional regulation by cAMP and its receptor protein. Annu Rev Biochem 62, 749-795.

Lessie, T. G. \& Neidhardt, F. C. (1967). Formation and operation of the histidine-degrading pathway in Pseudomonas aeruginosa. J Bacteriol 93, 1800-1810.

MacGregor, C. H., Wolff, J. A., Arora, S. K. \& Phibbs, P. V., Jr (1991). Cloning of a catabolite repression control ( $c r c)$ gene from Pseudomonas aeruginosa, expression of the gene in Escherichia coli, and identification of the gene product in Pseudomonas aeruginosa. J Bacteriol 173, 7204-7212.

MacGregor, C. H., Arora, S. K., Hager, P. W., Dail, M. B. \& Phibbs, P. V., Jr (1996). The nucleotide sequence of the Pseudomonas aeruginosa pyrE-crc-rph region and the purification of the $\operatorname{crc}$ gene product. J Bacteriol 178, 5627-5635.

Maleniak, T. C., Callan, R. J., Suh, S.-J. \& West, S. E. H. (1996). Pseudomonas aeruginosa $\mathrm{Vfr}$ regulates expression of numerous proteins including elastase, alkaline protease, and phospholipase C. In 96th General Meeting of the American Society for Microbiology. New Orleans, LA.

Nieuwkoop, A. J., Boylan, S. A. \& Bender, R. A. (1984). Regulation of hutUC operon expression by the catabolite gene activator protein-cyclic AMP complex in Klebsiella aerogenes. J Bacteriol 159, 934-939.

Ohman, D. E., Sadoff, J. C. \& Iglewski, B. H. (1980). Toxin Adeficient mutants of Pseudomonas aeruginosa PA103: isolation and characterization. Infect Immun 28, 899-908.

Pesci, E. C., Pearson, J. P., Seed, P. C. \& Iglewski, B. H. (1997). Regulation of las and $r h l$ quorum sensing in Pseudomonas aeruginosa. J Bacteriol 179, 3127-3132.

Phillips, A. T. \& Mulfinger, L. M. (1981). Cyclic adenosine $3^{\prime}, 5^{\prime}-$ monophosphate levels in Pseudomonas putida and Pseudomonas aeruginosa during induction and carbon catabolite repression of histidase synthesis. J. Bacteriol 145, 1286-1292.

Runyen-Janecky, L. J., Albus, A. M., Iglewski, B. H. \& West, S. E. H. (1996). The transcriptional activator Vfr binds to two apparently different binding sites in the promoters of Pseudomonas aeruginosa virulence genes. In 96th General Meeting of the American Society for Microbiology. New Orleans, LA.

Runyen-Janecky, L. J., Sample, A. K., Maleniak, T. C. \& West, S. E. H. (1997). A divergently transcribed open reading frame is located upstream of the Pseudomonas aeruginosa $v f r$ gene, a homolog of Escherichia coli crp. J Bacteriol 179, 2802-2809.

Schweizer, H. P. (1991). Escherichia-Pseudomonas shuttle vectors derived from pUC18/19. Gene 97, 109-112.

Schweizer, H. P. (1992). Allelic exchange in Pseudomonas aeruginosa using novel ColE1-type vectors and a family of cassettes 
containing a portable oriT and the counter-selectable Bacillus subtilis sacB marker. Mol Microbiol 6, 1195-1204.

Schweizer, H. P. (1993). Small broad-host-range gentamicin resistance gene cassettes for site-specific insertion and deletion mutagenesis. Biotechnology 15, 831-834.

Siegel, L. S., Hylemon, P. B. \& Phibbs, P. V., Jr (1977). Cyclic adenosine $3^{\prime}, 5^{\prime}$-monophosphate levels and activities of adenylate cyclase and cyclic adenosine $3^{\prime}, 5^{\prime}$-monophosphate phosphodiesterase in Pseudomonas and Bacteroides. J Bacteriol 129, 87-96.

Smith, P., Krohn, R., Hermanson, A. \& 7 other authors (1985). Measurement of protein using bicinchoninic acid. Anal Biochem 150, 76-85.

Stover, C. K., Pham, X. Q., Erwin, A. L. \& 28 other authors (2000). Complete genome sequence of Pseudomonas aeruginosa PAO1, an opportunistic pathogen. Nature 406, 959-964.

Ullmann, A. (1996). Catabolite repression: a story without end. Res Microbiol 147, 455-458.

Ullmann, A. \& Danchin, A. (1983). Role of cyclic AMP in bacteria. Adv Cyclic Nucleotide Res 15, 1-53.
West, S. E. H., Sample, A. K. \& Runyen-Janecky, L. J. (1994). The $v f r$ gene product, required for Pseudomonas aeruginosa exotoxin $\mathrm{A}$ and protease production, belongs to the cyclic AMP receptor protein family. J Bacteriol 176, 7532-7542.

Woese, C. R., Weisburg, W. G., Hahn, C. M., Paster, B. J., Zablen, L. B., Lewis, B. J., Macke, R. J., Ludwig, W. \& Stackebrandt, E. (1985). The physiology of purple bacteria: the gamma subdivision. Syst Appl Microbiol 6, 25-33.

Wolff, J. A., MacGregor, C. H., Eisenberg, R. C. \& Phibbs, P. V., Jr (1991). Isolation and characterization of catabolite repression control mutants of Pseudomonas aeruginosa PAO. J Bacteriol 173, 4700-4706.

Wood, D., Darlison, M. G., Wilde, R. J. \& Guest, J. R. (1984). Nucleotide sequence encoding the flavoprotein and hydrophobic subunits of the succinate dehydrogenase of Escherichia coli. Biochem J 222, 519-534.

Received 2 November 2001; revised 2 January 2002; accepted 31 January 2002. 